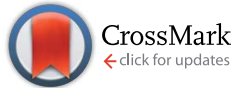

Cite this: RSC Adv., 2017, 7, 11550

Received 4th December 2016 Accepted 31st January 2017

DOI: $10.1039 / c 6 r a 27733 k$

rsc.li/rsc-advances

\section{Simulation of a conventional water treatment plant for the minimization of new emerging pollutants in drinking water sources: process optimization using response surface methodology $\dagger$}

\author{
A. Vijaya Bhaskar Reddy, ${ }^{a b}$ Zulkifli Yusop, ${ }^{b}$ Jafariah Jaafar, ${ }^{* a}$ Azmi B. Aris ${ }^{\text {bc }}$ \\ and Zaiton A. Majid ${ }^{a}$
}

This study describes the ability of conventional water treatment plants towards the removal of non-targeted new emerging pollutants (NEPs) by optimizing the variables such as $\mathrm{pH}$ and polyaluminium chloride (PAC), activated carbon, and chlorine $\left(\mathrm{Cl}_{2}\right)$ concentrations. Gas chromatography-mass spectrometry (GC-MS) was used for the separation and quantification of NEPs. Several NEPs, including ibuprofen, a drug expected to exhibit carcinogenicity at lower concentrations, were identified in selected river water samples. The simulation experiments were conducted using jar tests to minimize the turbidity, TOC, and ibuprofen concentrations in water samples. In addition, response surface methodology (RSM) with central composite design (CCD) was chosen for process optimization as well as to study the influences of the four factors viz., $\mathrm{pH}$ of the solution, PAC dosage, and activated carbon and $\mathrm{Cl}_{2}$ concentrations, on the treatment process. The quadratic models established for the three responses viz., turbidity, TOC, and ibuprofen removal, evidenced the lower values of $0.51 \mathrm{NTU}, 1.21 \mathrm{mg} \mathrm{L}^{-1}$, and $52.53 \%$ for the turbidity, TOC, and \% removal of ibuprofen, respectively, upon optimization of the selected variables. Moreover, the optimum conditions were evaluated, aiming at $90 \%$ ibuprofen removal, which was found to be attained at $26.50 \mathrm{ppm}$ of PAC, $49.20 \mathrm{ppm}$ of activated carbon, and $12.10 \mathrm{ppm}$ of $\mathrm{Cl}_{2}$ concentration at the $\mathrm{pH}$ value of 7.99. It was also confirmed that the experimental results are very close to the predicted values. In addition, the removal of other NEPs, turbidity, and TOC was also maximum under the optimized conditions. Finally, our results imply that NEPs are not only removed by coagulation itself, but also by adjusting other parameters such as $\mathrm{pH}$ and $\mathrm{Cl}_{2}$ concentration. Herein, the advantages of the RSM approach in achieving good predictions have been explained via conducting minimum number of experiments.

\section{Introduction}

The presence of new emerging pollutants (NEPs) in the environment is not new and they have remained in the environment for a long time. However, researchers are now trying to elucidate their presence and significance. These are often referred as contaminants of emerging concern (CEC) because of their risk associated with human health and the environment., ${ }^{1,2}$ These pollutants are entering the aquatic and terrestrial ecosystems by different routes and from different origins such as human and

${ }^{a}$ Department of Chemistry, Faculty of Science, Universiti Teknologi Malaysia, Johor Bahru 81300, Malaysia

${ }^{b}$ Institute of Environmental and Water Resource Management, Universiti Teknologi Malaysia, Johor Bahru 81300, Malaysia.E-mail: jafariah@kimia.fs.utm.my

${ }^{c}$ Department of Environmental Engineering, Faculty of Civil Engineering, Universiti Teknologi Malaysia, Johor Bahru 81300, Malaysia

$\dagger$ Electronic supplementary information (ESI) available. See DOI: $10.1039 / \mathrm{c} 6 \mathrm{ra} 27733 \mathrm{k}$ animal excretion, discharge from the production centers, disposition of surplus drugs etc. ${ }^{3}$ Among the various categories of emerging pollutants, pharmaceuticals and pesticide residues are considered as a major class as they are being detected in various ecosystems. Most of these pollutants raise considerable toxicological concerns since they are intrinsically and biologically active molecules. Different inspections in Europe and the US have revealed the presence of hundreds of these pollutants in trace amounts in surface water, ground water, drainage water, wastewater effluents, and alarmingly in tap water. ${ }^{4}$

The presence of NEPs, such as pharmaceuticals and pesticides, in surface water is of special concern since surface water is a key source of drinking water in the growing urban population areas. Therefore, the presence of these pollutants in the drinking water even at low concentrations, such as ppb or ppt, will impact human health due to chronic exposure. There are many widely used pharmaceuticals, such as acetaminophen, caffeine, carbamazepine, diclofenac, and ibuprofen, whose 
presence has been acknowledged in different water sources in many countries. ${ }^{5}$ In recent years, low concentrations of pharmaceutical compounds have been detected in drinking water supplies..$^{6-8}$ In addition, studies have also described the existence of various pharmaceuticals in surface water and the inability of conventional water treatment plants towards their removal. ${ }^{9,10}$ The extensive occurrence of these NEPs in surface waters may cause severe problems as these surface waters are preferably used for drinking purposes. ${ }^{11}$

Ibuprofen (2-(4-isobutylphenyl)propionic acid) is a derivative of propionic acid and is the leading non-steroidal antiinflammatory drug (NSAID) marketed in many countries. It is primarily used for musculoskeletal therapy and less importantly used as an analgesic. This drug is marketed in the doses of $400 \mathrm{mg}$ and $600 \mathrm{mg}$ as tablets or capsules and is extensively used all over the world. Among the top most drugs prescribed in the US in the year 2005, ibuprofen has occupied the $17^{\text {th }}$ position..$^{12,13}$ Numerous studies have confirmed the presence of ibuprofen in surface waters in the concentration range of $0.05-0.28 \mathrm{mg} \mathrm{L}^{-1}$. Therefore, it is necessary to evolve potential treatment practices for the removal of pharmaceuticals. Although, to date, there is no strong evidence regarding the adverse effects of ibuprofen on human health at trace levels, it would be beneficial to consider the principle of precaution and make the drinking water free from ibuprofen, thus reducing the potential long term risks. ${ }^{14}$ The negative impacts of ibuprofen on the biological systems were well studied and are inevitable. The toxic response of frog embryos towards various doses of ibuprofen using a frog embryo teratogenesis assay-Xenopus (FETAX) has been studied by Richards and Cole. The inhibition of embryo growth was noticed at a concentration of $30 \mathrm{mg} \mathrm{L}^{-1}$ after $96 \mathrm{~h}$ of exposure and no single embryo survived at concentrations above $70 \mathrm{mg} \mathrm{L}^{-1} \cdot{ }^{15}$ However, note that this concentration is extreme and has never been reported in the environment. The abovementioned results have been produced, thriving concerns in the scientific community, to come up with the possibility that certain drugs and their combinations may damage human health when people consume considerable amount of water every day for decades unlike the most specific foods. Hence, water quality regulations and safety limits have been established considering the existence of pharmaceuticals at trace levels.

In recent years, several studies have been reported on the removal of NEPs during the water treatment process. Some of these have monitored the removal of NEPs using WTP samples, whereas the majority of them have reported the removal of NEPs by conducting laboratory experiments. However, the process efficiency is somewhat different with the removal processes conducted on a laboratory scale and in the WTP. Numerous studies have shown that conventional treatment processes are not effective for the removal of these compounds. ${ }^{16-20}$ Although studies have proved that a combination of a natural system with any advanced treatment process will effectively work for the removal of organic pollutants, these technologies are very expensive to adopt in the water treatment plants of developing countries. ${ }^{21}$ However, coagulation, flocculation, and chlorination processes are extensively used to treat water as they are economical and simple to operate. A number of parameters, including type and dosage of coagulant/flocculant, $\mathrm{pH}$ of the water, mixing speed and time, temperature, and retention time, influence the process efficiency. In addition, the removal efficiency will increase with the appropriate optimization of these parameters. ${ }^{22}$ In conventional multifactor experiments, optimization is generally achieved by changing the values of a single parameter, whereas keeping all the other parameters constant under a specific set of conditions. However, this is not only a time-consuming, but also an inadequate process for achieving the optimum values since the interactions among these variables are neglected. Therefore, RSM has been proposed to overcome these disadvantages, in which the influence of individual factors and their interactions can be well studied. RSM helps to design the experiments, build the models, evaluate the effects of various parameters, and find the optimum values to obtain the best response. Further, RSM helps to find the possible interactions among the selected parameters using a very limited number of experiments. ${ }^{23}$

Although many studies have been reported for the removal of specific NEPs using RSM for process optimization, no studies have monitored the removal of turbidity and TOC during the removal of NEPs. ${ }^{24-27}$ These two parameters are also crucial when the studies are conducted for the drinking water purposes. Therefore, in the present study, we aimed to identify the nontargeted NEPs present in the river water samples and also to assess their removal along with the turbidity and TOC by optimizing the $\mathrm{pH}, \mathrm{PAC}$, and activated carbon and $\mathrm{Cl}_{2}$ concentrations. All the selected variables were optimized using RSM to achieve the best removal of NEPs. The effect of initial pH, coagulant dose, and activated carbon and $\mathrm{Cl}_{2}$ concentrations were explored using a full factorial CCD. All the experiments were performed using the jar test, a commonly used process to assess the treatment efficacy. Eventually, the goal of this study was to apply these results to minimize the NEPs in the drinking water sources, from which we can improve the quality of drinking water.

\section{Materials and methods}

\subsection{Reagents}

Ibuprofen and bisphenol A standards were supplied by SigmaAldrich (St Louis, MO, USA) with purities $>98 \%$. Other reference standards of benzene, ethyl benzene, xylene, toluene, and dodecene were obtained from Merck (Darmstadt, Germany). Acetonitrile, acetone, dichloromethane, hexane, ethyl acetate, and methanol were procured from S.D. fine chemicals (Mumbai, India) and were of analytical/HPLC grade. Activated carbon, PAC, and sodium hypochlorite were provided by a local water treatment plant (SAJ Skudai, Johor, Malaysia). SPE cartridges of Oasis HLB from Waters (Milford, MA, USA) and Chromabond C18 (Macherey-Nagel, Germany) were used for the clean-up and preconcentration of water samples. A Milli-Q water system was used to obtain ultrapure water (Millipore, Bedford, MA, USA).

\subsection{Sampling}

River water samples were collected in a single attempt during October 2015. A total of 25 liters of river water was collected and 
stored in a chiller. Sampling was carried out at the in-flow of the water treatment plant at Skudai River, a major drinking water source of Johor city in Malaysia. This river is the source of drinking water for more than three million population in Johor. The preliminary characteristics of the collected water samples are listed in Table S1.†

\subsection{Test variables}

Initially, 20 preliminary experiments were conducted to determine the range of the selected variables viz., $\mathrm{pH}$ value, PAC, activated carbon, and $\mathrm{Cl}_{2}$ concentrations. The working ranges of the selected variables were 6.0-8.0 for $\mathrm{pH}, 5.0-25 \mathrm{ppm}$ for PAC, 10-50 ppm for activated carbon, and 10-30 ppm for $\mathrm{Cl}_{2}$. The jar test experiments were performed and the variables were fixed considering the final turbidity of water $<1.0$ NTU. Moreover, the ranges for $\mathrm{pH}$ and $\mathrm{Cl}_{2}$ were selected following the guidelines of “Council Directive 98/83/EC (1998), established benchmarks for the quality of drinking water for human consumption in Europe".

\subsection{Jar test experiments}

Simulation of coagulation, flocculation, sedimentation, and chlorination practices of conventional treatment plants was achieved using scaled-down jar tests. The jar test experiments were carried out in $500 \mathrm{~mL}$ beakers with six paddle stirrers obtained from Phipps and Bird. The time and speed of the stirrer to increase and reduce the mixing speed was adjusted with an automatic controller. After adding PAC and activated carbon in their respective concentrations, the solution $\mathrm{pH}$ was adjusted in the range between 6.0 and 8.0 using $0.1 \mathrm{M}$ hydrogen chloride and sodium hydroxide solutions. The samples were rapidly stirred at a fixed speed of $140 \mathrm{rpm}$ for $5.0 \mathrm{~min}$ to provide fast mixing, followed by slow mixing at $45 \mathrm{rpm}$ for $10 \mathrm{~min}$ to provide flocculation, and then the solutions were kept undisturbed for $15 \mathrm{~min}$ for the particles to settle down. Later, the samples were collected from water about $2.0 \mathrm{~cm}$ depth from the surface to measure the turbidity, $\mathrm{pH}$, TOC, and removal percentage of the NEPs. The solution $\mathrm{pH}$ was measured using a $\mathrm{pH}$ meter (F-54 BW, Horiba, Japan) and the turbidity was measured by a standard nephelometric method using turbidimeter $(2100 \mathrm{~N}, \mathrm{HACH}, \mathrm{USA})$, followed by the percentage removal of NEPs using GC-MS.

\subsection{Sample analysis}

The identification and quantification of NEPs were carried out using GC-MS after solid phase extraction of the samples. Preconcentration of the non-targeted NEPs in the water samples was carried out by passing the samples through Chromabond C18 solid phase extraction cartridges. First, the preconditioning was carried out using $5.0 \mathrm{~mL}$ of methanol followed by $10 \mathrm{~mL}$ of Milli-Q water. After this, $500 \mathrm{~mL}$ of water samples were passed through the cartridges at a flow rate of $15 \mathrm{~mL} \mathrm{~min}^{-1}$. After removing the residual water from the cartridges, $5.0 \mathrm{~mL}$ of methanol was used for the elution. Finally, the extracts were evaporated to attain a final volume of $1.0 \mathrm{~mL}$ and were immediately injected for GC-MS analysis after the preparation of the samples. Among all the identified NEPs, ibuprofen was selected for the removal experiments. The removal percentage of ibuprofen by varying the selected parameters ( $\mathrm{pH}$ value, PAC, activated carbon, and $\mathrm{Cl}_{2}$ concentrations) in the jar test experiments was examined to select the most effective composition to achieve the best removal of ibuprofen and other NEPs.

\subsection{GC-MS operating conditions}

A HP 6890 gas chromatograph (GC) was equipped with a HP 7683 auto sampler and a HP 5973 mass detector (MSD) was equipped with a BPX5 column $(50 \mathrm{~m} \times 0.25 \mathrm{~mm}$ i.d. with $0.25 \mu \mathrm{m}$ thickness). The instrument parameters were applied as follows: injector temperature $250^{\circ} \mathrm{C}$, column oven temperature ranged from $50{ }^{\circ} \mathrm{C}(2.0 \mathrm{~min})$ to $110^{\circ} \mathrm{C}(2.0 \mathrm{~min})$ at $6.0^{\circ} \mathrm{C} \mathrm{min}^{-1}$, and then to $230{ }^{\circ} \mathrm{C}(4.0 \mathrm{~min})$ at $10{ }^{\circ} \mathrm{C} \mathrm{min}{ }^{-1}$, injection volume $2.0 \mu \mathrm{L}$ in splitless mode, and carrier gas flow rate of $1.0 \mathrm{~mL}$ $\min ^{-1}$. The transfer line and quadrupole temperatures were retained as $240^{\circ} \mathrm{C}$ and $150{ }^{\circ} \mathrm{C}$, respectively. The filament $(70 \mathrm{eV})$ was turned on after a $3.0 \mathrm{~min}$ run of the GC program. The GC injections were carried out using a Varian 8200 auto sampler via a $100 \mu \mathrm{L}$ syringe into a SPI/1079 split/splitless programmed temperature injector operated using the broad volume injection technique. The total analysis time was $30 \mathrm{~min}$ and the equilibration time was $0.5 \mathrm{~min}$. The analysis was achieved in selected ion recording (SIR) mode with a mass-to-charge ratio between $\mathrm{m} / z 50$ to 500 . The non-targeted NEPs were identified based on their $\mathrm{m} / \mathrm{z}$ values. The ion fragment $\mathrm{m} / \mathrm{z} 207$ was used for the confirmation of ibuprofen. The ion fragments $\mathrm{m} / \mathrm{z} 77, \mathrm{~m} / \mathrm{z} 92, \mathrm{~m} /$ $z 106, \mathrm{~m} / z$ 106, and $\mathrm{m} / \mathrm{z} 227$ were monitored for the confirmation of benzene, toluene, ethyl benzene, xylene, and bisphenol A, respectively. In addition, Table $\mathrm{S} 2 \dagger$ shows the list of nontargeted NEPs and their possible routes of entry into the drinking water sources.

\subsection{Sample preparation}

Prior to sample preparation, all the samples were sieved through a $150 \mu \mathrm{m}$ sieve and homogenized. Initially, various SPE cartridges, including Oasis HLB (200 mg and $500 \mathrm{mg}$ ) and Chromabond C18 (200 $\mathrm{mg}$ and $500 \mathrm{mg}$ ), were evaluated for the best extraction recoveries. First, $2.0 \mathrm{~mL}$ of methanol was added to the blank samples $(500 \mathrm{~mL})$ to extend the retention of analytes on the cartridges and were spiked with $1.0 \mu \mathrm{g} \mathrm{\textrm {L } ^ { - 1 }}$ of ibuprofen. From the results, it was found that the best recoveries were obtained in the range of $82.45-91.60 \%$ with Chromabond C18 cartridges using methanol as the eluent. It was also confirmed that the recoveries were best with $500 \mathrm{mg}$ rather than $200 \mathrm{mg}$ of sorbent, which confirms that the cartridges with $200 \mathrm{mg}$ of sorbent were not able to retain ibuprofen and other NEPs. Further, several organic solvents were tested for the best elution of ibuprofen loaded on the selected SPE cartridges. Multiple solvents, such as dichloromethane, acetonitrile, ethyl acetate, hexane, methanol, acetone, and their mixtures were used to test the recoveries. Moreover, PTFE containers were used instead of glass in the sample preparation process to avoid loss of the analytes because the analytes tend to bind to the glass that may result in a significant loss. The recoveries of the 
Table 1 The levels of the variables tested in 30 central composite designs

\begin{tabular}{llllll}
\hline & \multicolumn{5}{l}{ Range and level } \\
\cline { 2 - 6 } Parameter & $-\alpha$ & -1 & 0 & 1 & $\alpha$ \\
\hline$A:$ pH & 6.0 & 6.5 & 7.0 & 7.5 & 8.0 \\
$B:$ PAC (ppm) & 5.0 & 10 & 15 & 20 & 25 \\
$C:$ activated carbon (ppm) & 10 & 20 & 30 & 40 & 50 \\
$D: \mathrm{Cl}_{2}$ dosage (ppm) & 10 & 15 & 20 & 25 & 30 \\
& & & & & \\
\hline
\end{tabular}

analytes were determined as a ratio of the analytes concentration in the spiked samples to that of the standard calibration solutions. The best results were obtained when the elution was carried out using $5.0 \mathrm{~mL}$ of methanol.

\subsection{Response surface methodology}

It is necessary to design the experiments to adequately measure the selected responses. Generally, it is highly complicated to represent the relation between the selected responses (turbidity, TOC, and ibuprofen removal) and independent variables $(\mathrm{pH}$,
PAC, activated carbon, and $\mathrm{Cl}_{2}$ concentrations) using a first-order model. Therefore, a model that is capable to approximate the response in a region closer to the optimum is normally required and in most cases, a second-order model is sufficient. Hence, in this study, we selected CCD, which is a very efficient tool to fit in the second-order models. The required number of experiments for CCD are as follows: standard $2^{k}$ cube points, $2 \times k$ axial points axially fixed at a distance say $\alpha$, from the center to produce the quadratic terms, and replicate tests at the center of the experimental region, where $k$ denotes the number of variables. The independent evaluation of the experimental error is very important and can be obtained from the replicates of a test at the center. Commonly, five to seven center runs are recommended to know the exact experimental error. A CCD with 4 factors and 6 replicate tests at the center results a total of $16+08+06=30$ runs. All 30 experiments were randomly conducted to avoid the impact of uncontrolled variables on the responses.

The composed data was statistically evaluated applying a regression analysis to ascertain if any relationship existed among the factors and their responses were examined. Further, a regression design was employed to model the response as a mathematical function of a few continuous factors and where

Table 2 The central composite design and response results for the four selected variables

\begin{tabular}{|c|c|c|c|c|c|c|c|c|c|}
\hline \multirow[b]{2}{*}{ Std. } & \multirow[b]{2}{*}{ Run } & \multirow[b]{2}{*}{ Block } & \multirow{2}{*}{$\begin{array}{l}\text { Factor } 1 \\
A: \\
\text { pH }\end{array}$} & \multirow{2}{*}{$\begin{array}{l}\text { Factor } 2 \\
B: \\
\text { PAC ppm }\end{array}$} & \multirow{2}{*}{$\begin{array}{l}\text { Factor } 3 \\
C: \text { Act } \\
\text { car ppm }\end{array}$} & \multirow{2}{*}{$\begin{array}{l}\text { Factor } 4 \\
\mathrm{Cl}_{2} \mathrm{ppm}\end{array}$} & \multirow{2}{*}{$\begin{array}{l}\begin{array}{l}\text { Response } \\
1\end{array} \\
\begin{array}{l}\text { Turbidity removal } \\
\text { (NTU) }\end{array}\end{array}$} & \multirow{2}{*}{$\begin{array}{l}\text { Response } \\
2 \\
\text { TOC removal } \\
\mathrm{mg} \mathrm{L}^{-1}\end{array}$} & \multirow{2}{*}{$\begin{array}{l}\text { Response } 3 \\
\begin{array}{l}\text { Ibuprofen removal } \\
(\%)\end{array}\end{array}$} \\
\hline & & & & & & & & & \\
\hline 1 & 12 & Block 1 & 7.50 & 20.00 & 20.00 & 25.00 & 0.77 & 1.91 & 39.11 \\
\hline 2 & 10 & Block 1 & 7.50 & 10.00 & 20.00 & 25.00 & 0.41 & 1.48 & 39.23 \\
\hline 5 & 07 & Block 1 & 6.50 & 20.00 & 40.00 & 15.00 & 0.51 & 1.38 & 29.44 \\
\hline 6 & 27 & Block 1 & 7.00 & 15.00 & 30.00 & 15.00 & 0.87 & 1.97 & 48.10 \\
\hline 7 & 24 & Block 1 & 7.00 & 15.00 & 30.00 & 25.00 & 0.87 & 1.81 & 51.89 \\
\hline 8 & 15 & Block 1 & 6.50 & 20.00 & 40.00 & 25.00 & 0.93 & 1.81 & 40.62 \\
\hline 9 & 30 & Block 1 & 7.00 & 15.00 & 30.00 & 15.00 & 0.89 & 2.01 & 48.18 \\
\hline 10 & 02 & Block 1 & 7.50 & 10.00 & 20.00 & 15.00 & 0.93 & 2.32 & 46.65 \\
\hline 15 & 06 & Block 1 & 7.50 & 10.00 & 40.00 & 15.00 & 0.75 & 2.31 & 48.03 \\
\hline 16 & 13 & Block 1 & 6.50 & 10.00 & 40.00 & 25.00 & 1.11 & 2.54 & 48.80 \\
\hline 17 & 29 & Block 1 & 7.00 & 15.00 & 30.00 & 15.00 & 0.91 & 1.91 & 49.19 \\
\hline 18 & 03 & Block 1 & 6.50 & 20.00 & 20.00 & 15.00 & 0.89 & 1.91 & 48.38 \\
\hline 19 & 20 & Block 1 & 7.00 & 25.00 & 30.00 & 20.00 & 0.91 & 1.31 & 45.84 \\
\hline 20 & 04 & Block 1 & 7.50 & 20.00 & 20.00 & 15.00 & 0.95 & 1.99 & 48.87 \\
\hline 21 & 21 & Block 1 & 7.00 & 15.00 & 10.00 & 20.00 & 0.46 & 1.54 & 52.27 \\
\hline 22 & 26 & Block 1 & 7.00 & 15.00 & 30.00 & 15.00 & 0.87 & 1.90 & 47.51 \\
\hline 23 & 09 & Block 1 & 6.50 & 10.00 & 20.00 & 25.00 & 0.51 & 1.73 & 54.20 \\
\hline 24 & 23 & Block 1 & 7.00 & 15.00 & 30.00 & 30.00 & 0.55 & 1.58 & 48.88 \\
\hline 25 & 14 & Block 1 & 7.50 & 10.00 & 40.00 & 25.00 & 1.05 & 2.21 & 54.60 \\
\hline 26 & 08 & Block 1 & 7.50 & 20.00 & 40.00 & 15.00 & 0.64 & 1.49 & 59.33 \\
\hline
\end{tabular}


'good' model criterion estimates were desired. ${ }^{28}$ Every individual response of $Y$ can be expressed using a mathematical equation that correlates the response surface. The responses can also be described by second-order polynomial equations, according to eqn (1)

$$
Y=f(x)=\beta_{0}+\sum_{i=1}^{k} \beta_{i} x_{i}+\sum_{i=1}^{k} \beta_{i i} x_{i}^{2}+\sum_{i=1}^{k} \sum_{j=1+i}^{k} \beta_{i j} x_{i} x_{j}
$$

where $Y$ stands for the predicted response (turbidity removal, ibuprofen removal, and TOC removal) employed as the dependent variable, $k$ denotes the number of independent variables, $x_{i}$ and $x_{j}$ denotes the independent variables that influence $Y, \beta_{0}$ is a constant coefficient, and $\beta_{i}, \beta_{i j}$, and $\beta_{i i}$ are the coefficients of linear, interaction, and quadratic terms, respectively. The actual design used in this study is displayed in Table 1. A multiple linear regression analysis was conducted to estimate the coefficient parameters using Design-Expert software (version 8.0.1). The software was further utilized to express the 3D surface and $2 \mathrm{D}$ contour plots of the response models.

To find the acceptable experimental domain, preliminary assessments were conducted to regulate the more effective ranges of $\mathrm{pH}$ value, $\mathrm{PAC}$, activated carbon, and $\mathrm{Cl}_{2}$ concentrations prior to designing the experimental runs. From the preliminary investigations, it was observed that coagulation was most effective in the PAC range between 5 and 25 ppm, activated carbon range between 10 and $50 \mathrm{ppm}, \mathrm{Cl}_{2}$ dosage between 10 and $30 \mathrm{ppm}$, and $\mathrm{pH}$ range between 6.0 and 8.0. After determining the ranges of the variables, they were coded to lie at \pm 1 for the factorial points, 0 for the center points, and $\pm \alpha$ for the axial points. The codes were determined as a function of the range of interest of each factor. A CCD experiment with 16 factorial points, 8 axial points, and 6 additional trials (run numbers 25-30) as replicates of the center point are presented in Table 2.

\section{Results and discussion}

\subsection{Statistical analysis}

The experimental outcomes, experimental design model, and the predicted turbidity, TOC, and ibuprofen removal are presented in Table 2. The CCD model was used to develop mathematical equations, in which each response $Y=f(x)$ was determined as a function of $\mathrm{pH}$ value, $\mathrm{PAC}$, activated carbon, and $\mathrm{Cl}_{2}$ concentrations. The results of the fitted models for turbidity, TOC, and ibuprofen removal are presented in eqn (2)-(4).

Turbidity removal $Y(\mathrm{NTU})=0.98+0.13 A-8.333 \times 10^{-5} B+$ $0.10 C+8.970 \times 10^{-5}+0.15 A^{2}-0.085 B^{2}-0.040 C^{2}-0.041 D^{2}+$ $0.13 A B-0.015 A C-0.040 A D-0.31 B C+0.18 B D+0.64 C D$

TOC removal $Y\left(\mathrm{mg} \mathrm{L}^{-1}\right)=1.88-0.051 A-0.49 B+0.11 C-$ $0.19 D+0.85 A^{2}-0.072 B^{2}-0.20 C^{2}-0.070 D^{2}+0.60 A B+$

$0.032 A C+0.21 A D-0.42 B C+0.68 B D+0.87 C D$

Ibuprofen removal $(\%)=52.41+6.09 A+0.47 B-1.44 C+3.42 D$ $-6.10 A^{2}-7.17 B^{2}-2.57 C^{2}-8.11 D^{2}+7.19 A B+25.04 A C-$

$12.59 A D+2.94 B C-6.20 B D+11.66 C D$
ANOVA results for the removal of turbidity, TOC, and ibuprofen are listed in Table 3. From the experimental results, the $P$-value of the regression model equation i.e., $0.0001(P<$ 0.05) confirms that the results are best fitted to second-order polynomial model. As presented in Table 3, the model was found to be significant at a 95\% confidence level with all $p$-values of regression $\leq 0.05$, following the $F$-test. Moreover, the lack-of-fit values were also determined from the experimental error (pure error) and residuals. $F$-Values for the lack-of-fit are $4.82,1.86$, and 4.18 for turbidity, TOC, and ibuprofen removal, respectively, and indicate the significance of the model correlation among the selected variables and resulting process responses, as depicted in Fig. 1. Further, the lack-of-fit tests help to find the breakdown of a model and to represent the data of the points in an experimental domain, which are not incorporated in the regression. If a model is significant and contains one or more important terms that explain that the model does not suffer from the lack-of-fit, it does not necessarily mean that the model is good. If the experimental domain is absolutely noisy or some crucial variables are omitted from the experiment, there is a possibility to obtain a high residual value in the data, which was not explained by the model. Thus, the coefficient of determination, denoted by $R^{2}$, must be considered to measure any model's overall performance. Moreover, the adjusted $R^{2}$ allows for the degrees of freedom associated with the sum of the squares also to be considered in the lack-of-fit test, which is an approximate value of $R^{2}$. When the difference between $R^{2}$ and adjusted $R^{2}$ values is vast it indicates the involvement of non-significant terms in the model. In addition, the value of $R^{2}$ and $R^{2}$ (adj) for all the three parameters approves the model's accuracy. Moreover, the $R^{2}$ values are not significantly different in the parity plots of the experimental and predicted values, as shown in Table 3. In addition, there is no strong evidence for the departures of normality from the normal probability plots of the residuals for turbidity, TOC, and ibuprofen removal, as shown in Fig. 2. As seen in Fig. 2, all the points in the plot form a fairly straight line, and hence, the normality hypothesis was relatively satisfied. As a result, we can say that the model is fairly suitable to describe the removal of turbidity, TOC, and ibuprofen using response surface methodology varying the $\mathrm{pH}$ value, $\mathrm{PAC}$, activated carbon, and $\mathrm{Cl}_{2}$ concentrations. Hence, the second-order models, as presented in eqn (2)-(4), used to measure the responses are significant and acceptable.

\subsection{Interpretation of the operational parameters using the response surface and counter plotting}

According to the RSM model, the solution pH, PAC, activated carbon, and $\mathrm{Cl}_{2}$ concentrations are the terms that influence the removal of turbidity, TOC, and ibuprofen at a 95\% confidence level. Further, 3D plots and their corresponding contour plots were described to better explain the independent variables and their influence on the removal of turbidity, TOC, and ibuprofen, as shown in Fig. 3. In Fig. 3(a)-(c), the $\mathrm{pH}$ value and $\mathrm{Cl}_{2}$ concentration were kept constant at 7.0 and $20 \mathrm{ppm}$, respectively, and the influence of PAC and activated carbon on the 
Table 3 ANOVA results for the three responses viz., turbidity, TOC, and ibuprofen removal

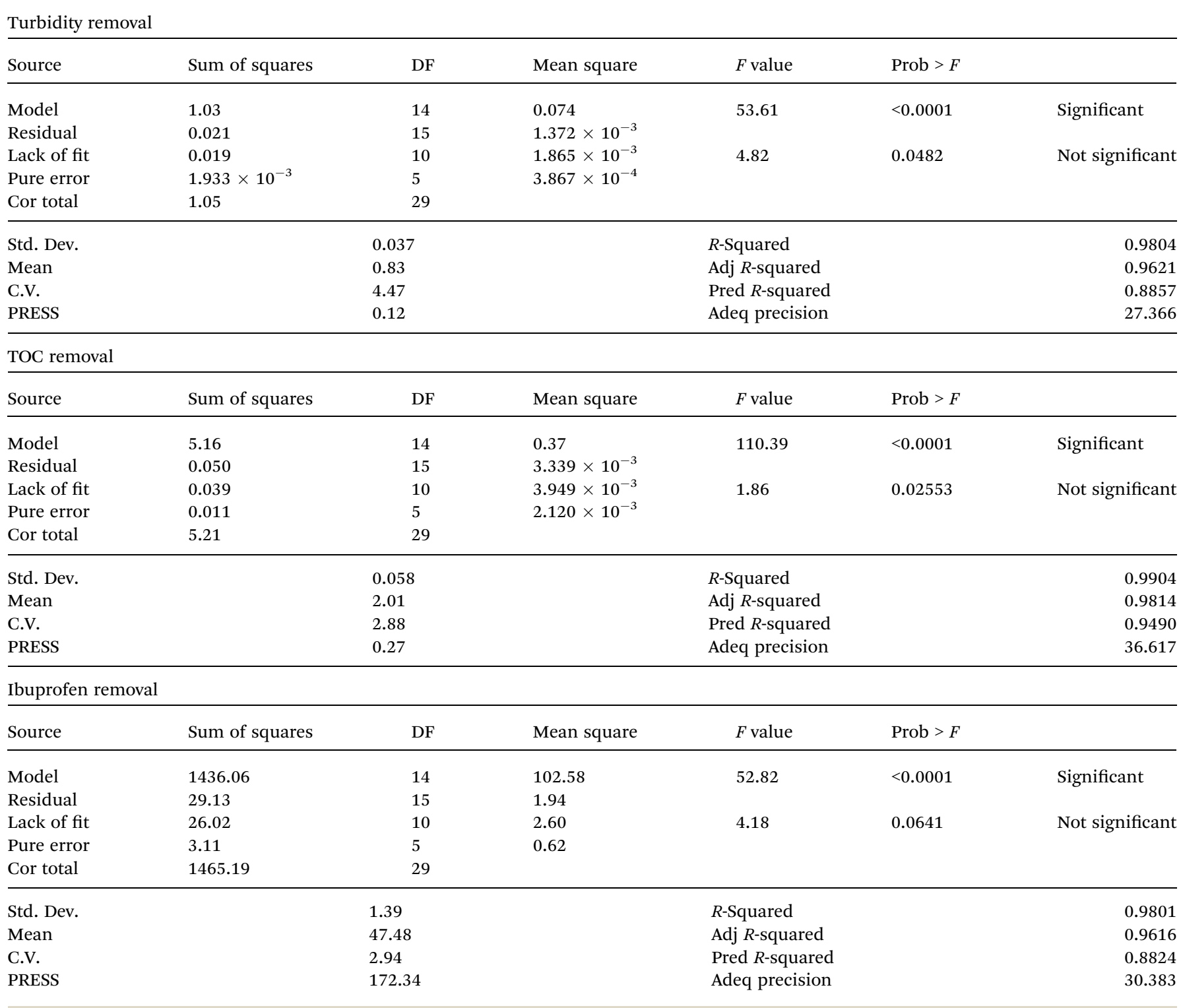

(a)

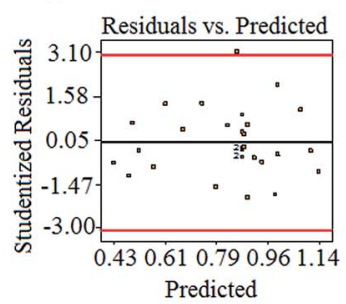

(b)

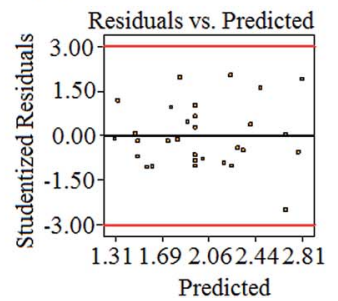

(c)

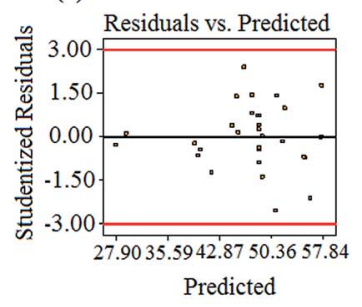

Fig. 1 The design expert plots of residuals vs. predicted values for (a) turbidity, (b) TOC, and (c) ibuprofen removal from water samples.

removal efficiency was studied. The best removal of turbidity was obtained at $22.38 \mathrm{ppm}$ and $10.47 \mathrm{ppm}$ of PAC, and 48.18 ppm and $15.43 \mathrm{ppm}$ of activated carbon. The resultant turbidity of water at the abovementioned concentrations was
0.51 NTU. A relatively higher turbidity was observed between these concentrations and a lower turbidity was observed beyond the abovementioned limits. Moreover, the best removal of TOC i.e., $1.21 \mathrm{mg} \mathrm{\textrm {L } ^ { - 1 }}$ was observed at $22.86 \mathrm{ppm}$ of PAC and 
(a)

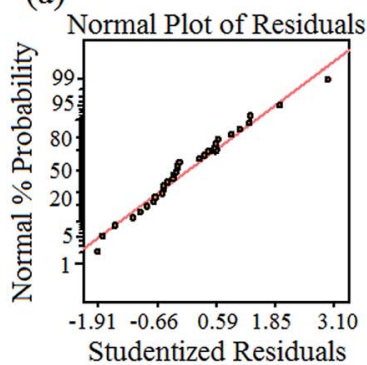

(b)

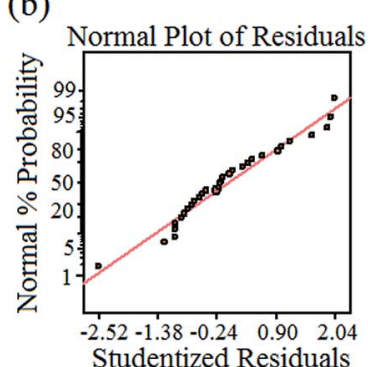

(c)
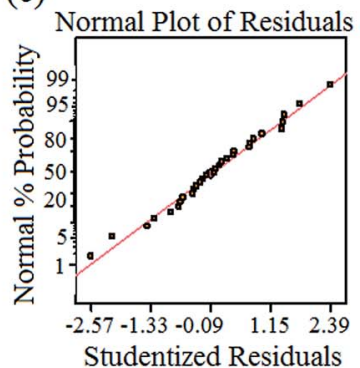

Fig. 2 The normal probability plots of the standardized residual for (a) turbidity, (b) TOC, and (c) ibuprofen removal.

43.20 ppm of activated carbon. The removal efficiency was increased upon increasing the concentrations of PAC and activated carbon up to $25 \mathrm{ppm}$ and $50 \mathrm{ppm}$, respectively, and then decreased upon further increase in their concentrations. Moreover, the best removal of ibuprofen (52.53\%) was observed at $13.97 \mathrm{ppm}$ of PAC and $20.69 \mathrm{ppm}$ of activated carbon. Slightly lower removal rates for ibuprofen were obtained when the concentrations deviated from the abovementioned values. Overall, the removal of turbidity, TOC, and ibuprofen is highly
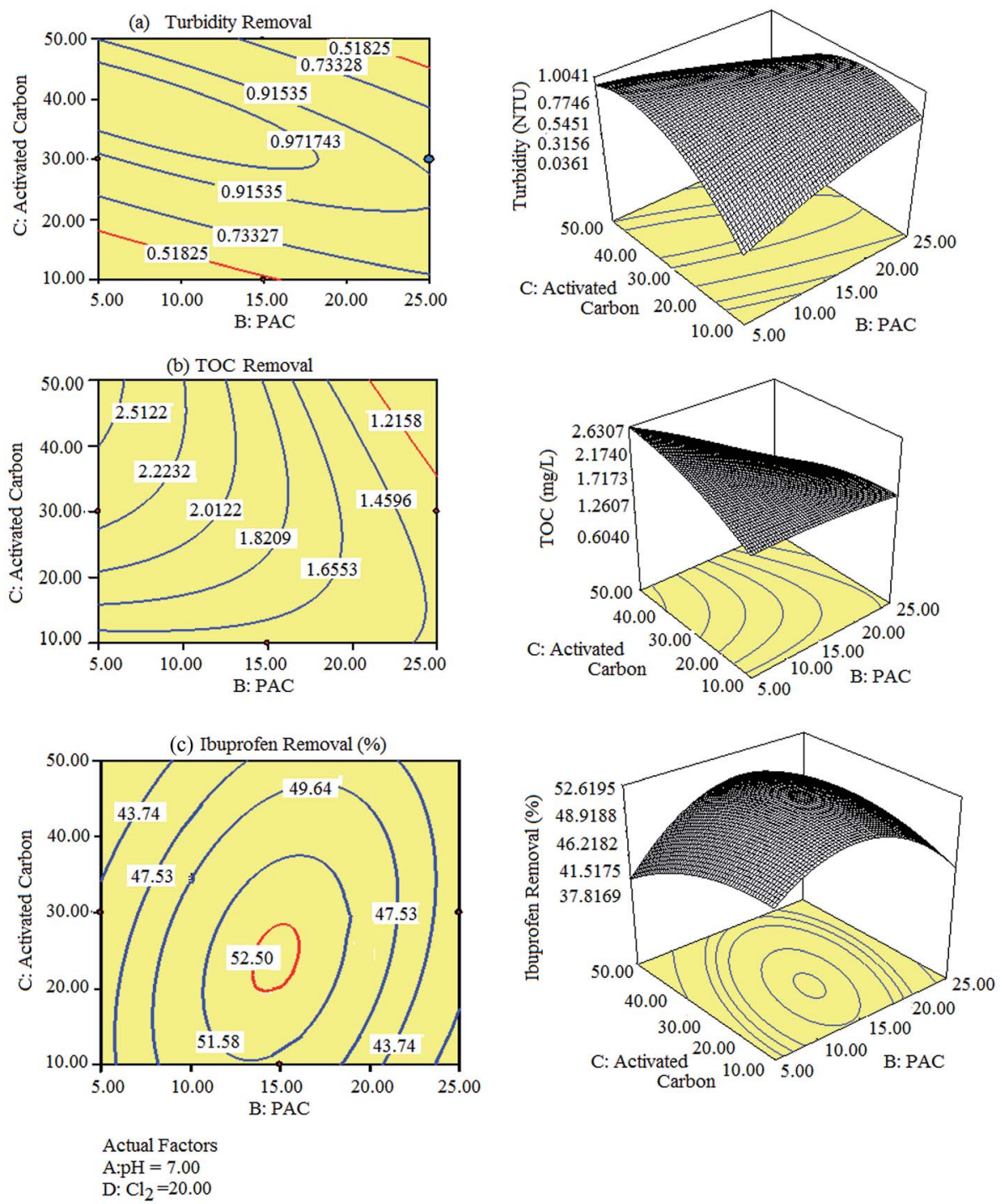

Fig. 3 Representative 3D images and their 2D contour plots obtained for the removal of (a) turbidity, (b) TOC, and (c) ibuprofen. 
dependent on PAC and activated carbon, whereas slightly dependent on the initial $\mathrm{pH}$ value and $\mathrm{Cl}_{2}$ concentration.

\subsection{NEPs removal during the water treatment process}

It is not easy to evaluate the removal of NEPs at a particular stage in the conventional treatment processes as the processes depend on several aspects (e.g., system arrangements, operation schedules, treatment conditions, and influent loadings in source waters) in WTPs. Hence, a detailed study is required to investigate the removal mechanism of various pollutants. In this study, we described the removal of several non-targeted NEPs at each stage of treatment in the WTP by comparing it with laboratory scale experiments. Generally, coagulation is the most common process for the removal of colloidal particles. However, research has disclosed that the coagulation process itself is not effective for the elimination of pollutants. Several researchers have reported that the coagulation process is capable of removing only $15 \%$ of pharmaceuticals and other NEPs. ${ }^{29-31}$ In addition, the removal of micropollutants during the coagulation process is not only achieved by coagulation, but also by the combination of adsorption and electrostatic interactions between the micropollutants and the coagulant. Then, the chlorination step is effective to eliminate microbial activity and it triggers the oxidation of organic materials. Moreover, it starts the ring cleavage of aromatic compounds and helps in the formation of oxidative by-products from pesticides and pharmaceuticals. ${ }^{31}$ However, the efficiency of chlorination is less than coagulation towards the removal of micropollutants. ${ }^{28}$ Moreover, it is highly complicated to determine the removal of NEPs at each stage as we do not handle these three processes side-by-side. Therefore, laboratory scale chlorination experiments were conducted to determine the efficacy of chlorination by varying the $\mathrm{Cl}_{2}$ concentration and solution $\mathrm{pH}$. The turbidity, TOC, and NEPs removal rates were satisfactory when maintained at a higher $\mathrm{Cl}_{2}$ concentration i.e. $20 \mathrm{ppm}$. However, low removal rates of the NEPs were obtained using the higher $\mathrm{Cl}_{2}$ concentration (20 ppm) at a lower $\mathrm{pH}(6.0)$. Therefore, the $\mathrm{Cl}_{2}$ concentration and $\mathrm{pH}$ value were maintained at $20 \mathrm{ppm}$ and 7.0, respectively, for the best removal of NEPs, turbidity, and TOC. A previous study also recommended that the solution $\mathrm{pH}$ plays an important role in the effective removal of pollutants. ${ }^{31}$ Our results suggest that the optimization of control factors, such as $\mathrm{pH}$ and $\mathrm{Cl}_{2}$ concentration, are necessary for the effective removal of micropollutants during the disinfection process.

\subsection{Process optimization}

The optimum values to achieve a $90 \%$ removal of ibuprofen were determined first in coded units, and then converted into un-coded units using eqn (2)-(4). A solution $\mathrm{pH}$ of $7.99, \mathrm{Cl}_{2}$ concentration of $12.10 \mathrm{ppm}$, PAC concentration of 26.50 , and activated carbon concentration of $49.20 \mathrm{ppm}$ were found as the optimum conditions using the RSM model. The experiments were repeated three times under these optimum conditions and the ibuprofen removal efficiencies were found to be $89.20 \%$,

Table 4 Estimation of the second-order response surface parameters for the removal of ibuprofen

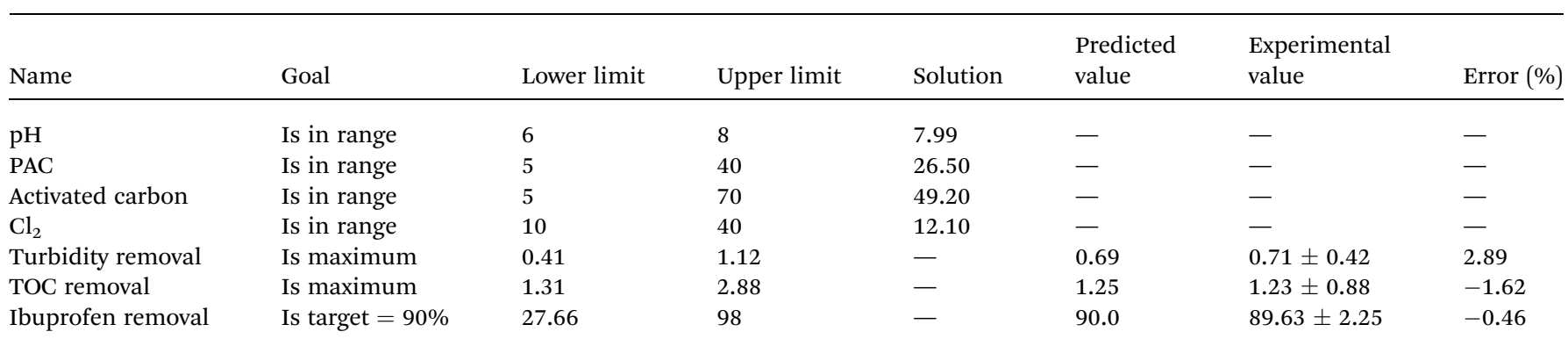

(a)

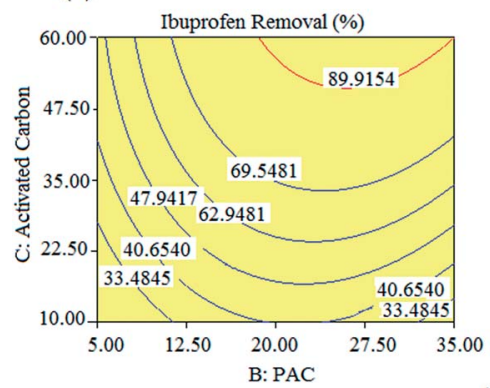

(b)

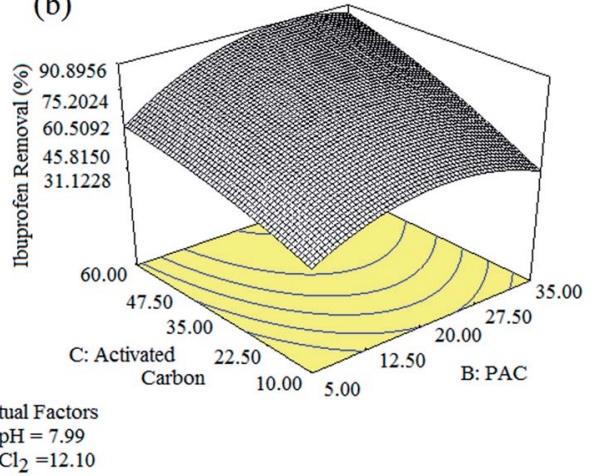

Fig. 4 2D contour plots and their 3D surface plots obtained for the removal of ibuprofen under the optimized conditions. 

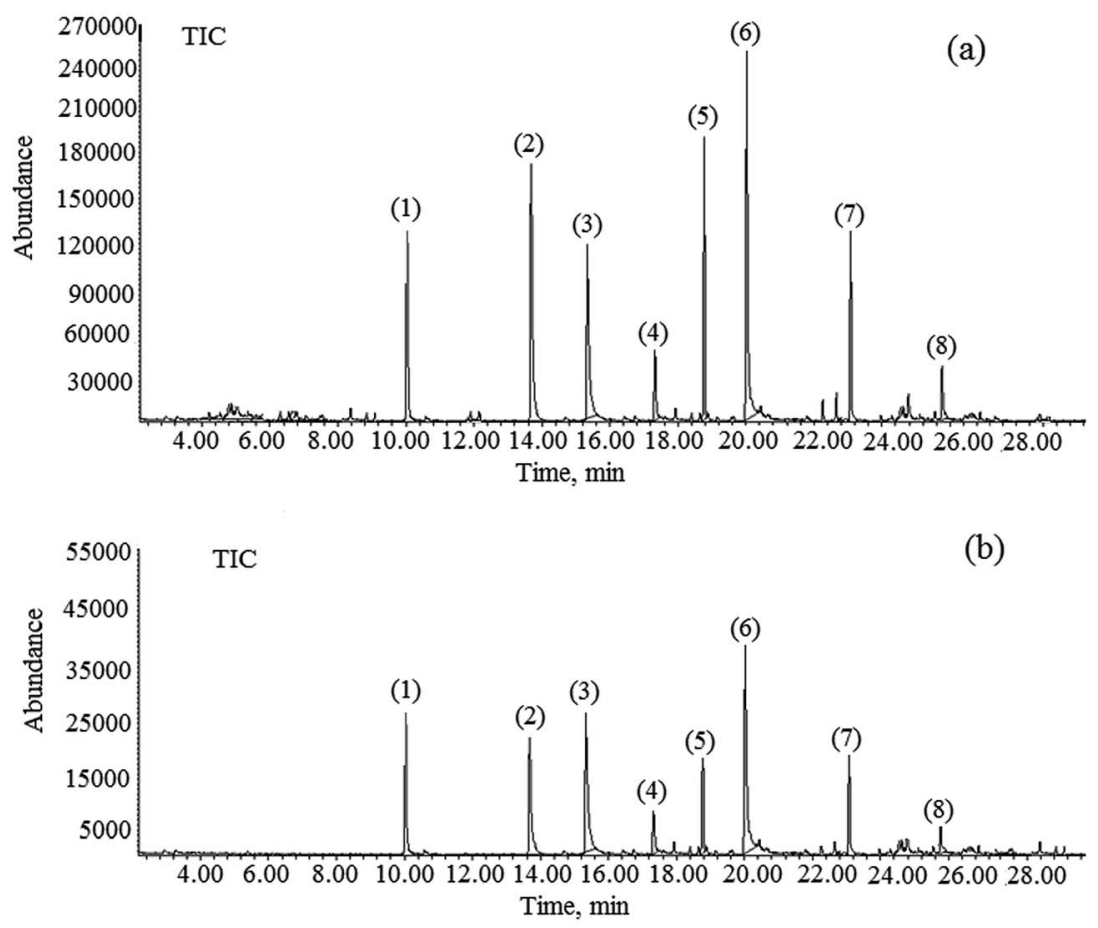

Fig. 5 Gas chromatograms of all non-targeted NEPs viz., (1) benzene, (2) fluorides, (3) toluene, (4) ethyl benzene, (5) xylene, (6) bisphenol A, (7) dodecene, and (8) ibuprofen (a) before and (b) after the optimization process.

$91.60 \%$, and $88.10 \%$ with a $\%$ RSD $<3.0$ (Table 4 ). The average removal efficiency of ibuprofen was $89.63 \%$, which is closer to the model prediction of $90 \%$. Fig. $4(\mathrm{a})$ and (b) illustrate the 3D response surface plot and 2D contour plot of the quadratic models for $\mathrm{pH}$ value, PAC, activated carbon, and $\mathrm{Cl}_{2}$ concentrations with respect to ibuprofen removal. As shown in Fig. 4(a), ibuprofen removal increased upon increasing the PAC and activated carbon concentrations. However, the concentrations of $\mathrm{Cl}_{2}$ and PAC were moderately maintained to avoid the formation of residual $\mathrm{Cl}_{2}$ in the final treated water. Hence, the concentration of $\mathrm{Cl}_{2}$ was restricted to $12.10 \mathrm{ppm}$ and that of PAC was restricted to $35 \mathrm{ppm}$ to avoid further health issues due to residual $\mathrm{Cl}_{2}$ if present in the final treated water. In addition, the concentrations of other non-targeted NEPs were also found to be minimal at this optimized level, which is an added advantage of the procedure. The gas chromatograms of the identified NEPs before and after the optimization process are shown in Fig. 5.

\section{Conclusions}

The benefits of RSM to attain the optimal conditions used during a conventional water treatment process via adjusting the $\mathrm{pH}$ value, $\mathrm{PAC}$, activated carbon, and $\mathrm{Cl}_{2}$ concentrations were demonstrated in this study. Further, the RSM model was enforced as an experimental design to explore the optimal variables to remove the turbidity, TOC, and ibuprofen from river water samples by adjusting the $\mathrm{pH}$ value and $\mathrm{PAC}$, activated carbon, and $\mathrm{Cl}_{2}$ concentrations. The impact and interactions of the four operating variables, including the initial $\mathrm{pH}$ value and
$\mathrm{PAC}$, activated carbon, and $\mathrm{Cl}_{2}$ concentrations, during the water treatment process were examined. The results of this study have proved that RSM is a powerful statistical optimization and modeling tool for the removal of pollutants using a conventional water treatment process. The models were represented as $3 \mathrm{D}$ response surfaces and 2D contour graphs to better explain the optimal performance. Moreover, the four variables viz., $\mathrm{pH}$ value and PAC, activated carbon, and $\mathrm{Cl}_{2}$ concentrations play crucial roles in minimizing the turbidity, TOC, and ibuprofen and other NEPs in the drinking water sources.

\section{Conflict of interest}

The authors declared that there is no conflict of interest.

\section{Acknowledgements}

The authors would like to acknowledge the Research University Grant, Universiti Teknologi Malaysia for supporting their postdoctoral fellowship and extended their thanks to the Ministry of Education Malaysia for funding the LRGS Grant on Water Security entitled Protection of Drinking Water: Source Abstraction and Treatment (203/PKT/6720006).

\section{References}

1 S. Sauve and M. Desrosiers, A review of what is an emerging contaminant, Chem. Cent. J., 2014, 8, 1-5.

2 V. Geissen, H. Mol, E. Klumpp, G. Umlauf, M. Nadal, M. Van der Ploeg, S. E. A. T. M. Van de Zee and C. J. Ritsema, 
Emerging pollutants in the environment: a challenge for water resource management, International Soil and Water Conservation Research, 2015, 3, 57-65.

3 L. Lamastra, M. Balderacchi and M. Trevisan, Inclusion of emerging organic contaminants in ground water monitoring plans, MethodsX, 2016, 3, 459-476.

4 A. Vijaya Bhaskar Reddy, V. Madhavi, K. Gangadhara Reddy and G. Madhavi, Remediation of chlorpyrifos contaminated soils by laboratory synthesized zero-valent nanoiron particles: effect of $\mathrm{pH}$ and aluminium salts, Journal of Chemistry, 2013, 521045.

5 S. E. Paul, J. Gibs, E. T. Furlong, M. T. Meyer, Z. D. Steven and R. L. Lee, Efficiency of conventional drinking-watertreatment processes in removal of pharmaceuticals and other organic compounds, Sci. Total Environ., 2007, 377, 255-272.

6 C. Postigo and S. D. Richardson, Transformation of pharmaceuticals during oxidation/disinfection processes in drinking water treatment, J. Hazard. Mater., 2014, 279, 461-475.

7 C. C. Gordon, C. H. Yen and C. L. Wang, Monitoring and removal of residual phthalate esters and pharmaceuticals in the drinking water of Kaohsiung City, Taiwan, J. Hazard. Mater., 2014, 277, 53-61.

8 S. Gabarron, W. Gernjak, F. Valero, A. Barcelo, M. Petrovic and I. R. Roda, Evaluation of emerging contaminants in a drinking water treatment plant using electrodialysis reversal technology, J. Hazard. Mater., 2016, 309, 192-201.

9 S. R. Mozaz, M. Ricart, M. K. Schulmeyer, G. Helena, C. Bonnineau, L. Proia, M. L. Alda, S. Sabater and D. Barcelo, Pharmaceuticals and pesticides in reclaimed water: efficiency assessment of a microfiltration-reverse osmosis (MF-RO) pilot plant, J. Hazard. Mater., 2015, 282, 165-173.

10 Q. Bu, B. Wang, J. Huang, S. Deng and G. Yu, Pharmaceuticals and personal care products in the aquatic environment in China: a review, J. Hazard. Mater., 2013, 262, 189-211.

11 A. Ziylan and N. H. Ince, The occurrence and fate of antiinflammatory and analgesic pharmaceuticals in sewage and fresh water: treatability by conventional and nonconventional processes, J. Hazard. Mater., 2011, 187, 24-36.

12 A. Loudiki, W. Boumya, H. Hammani, H. Nasrellah, Y. El Bouabi, M. Zeroual, A. Farahi, S. Lahrich, K. Hnini, M. Achak, M. Bakasse and M. A. El Mhammedi, Ibuprofen analysis in blood samples by palladium particlesimpregnated sodium montmorillonite electrodes: validation using high performance liquid chromatography, Mater. Sci. Eng., C, 2016, 69, 616-624.

13 A. Patel, G. H. Panter, H. T. Trollope, Y. C. Glennon, S. F. Owen, J. P. Sumpter and M. R. Weaver, Testing the "read-across hypothesis" by investigating the effects of ibuprofen on fish, Chemosphere, 2016, 163, 592-600.

14 V. Matozzo, S. Rova and M. G. Marin, The nonsteroidal antiinflammatory drug, ibuprofen, affects the immune parameters in the clam Ruditapes philippinarum, Mar. Environ. Res., 2012, 79, 116-121.
15 M. R. Sean and S. E. Cole, A toxicity and hazard assessment of fourteen pharmaceuticals to Xenopus laevis larvae, Ecotoxicology, 2006, 15, 647-656.

16 J. O. Alissa, D. A. Lytle, S. Harmon, K. Vu, H. Chait and D. D. Dionysiou, Removal of strontium from drinking water by conventional treatment and lime softening in bench-scale studies, Water Res., 2016, 103, 319-333.

17 M. J. Mckie, A. A. Susan and R. C. Andrews, Conventional drinking water treatment and direct biofiltration for the removal of pharmaceuticals and artificial sweeteners: a pilot-scale approach, Sci. Total Environ., 2016, 544, 10-17.

18 C. F. Lopez, J. M. G. Navarro, J. J. Padilla and J. R. Parsons, Comparison of the removal efficiencies of selected pharmaceuticals in waste water treatment plants in the region of Murcia, Spain, Ecological Engineering, 2016, 95, 811-816.

19 V. Reguero, R. L. Fernandez, J. Fermoso, O. Prieto, P. Pocostales, R. Gonzalez, R. Irusta and S. Villaverde, Comparison of conventional technologies and a submerged membrane photocatalytic reactor (SMPR) for removing trihalomethanes (THM) precursors in drinking water treatment plants, Desalination, 2013, 330, 28-34.

20 N. G. Vaquero, E. Lee, R. J. Castaneda, J. Cho and J. A. L. Ramirez, Comparison of drinking water pollutant removal using a nanofiltration pilot plant powered by renewable energy and a conventional treatment facility, Desalination, 2014, 347, 94-102.

21 S. Zhang, S. Gitungo, L. Axe, J. E. Dyksen and R. F. Raczko, A pilot plant study using conventional and advanced water treatment processes: evaluating removal efficiency of indicator compounds representative of pharmaceuticals and personal care products, Water Res., 2016, 105, 85-96.

22 Y. Chen, J. Vymazal, T. Brezinova, M. Kozeluh, L. Kule, J. Huang and Z. Chen, Occurrence, removal and environmental risk assessment of pharmaceuticals and personal care products in rural wastewater treatment wetlands, Sci. Total Environ., 2016, 566-567, 1660-1669.

23 D. Cheng, W. Gong and N. Li, Response surface modeling and optimization of direct contact membrane distillation for water desalination, Desalination, 2016, 394, 108-122.

24 E. Radaei, M. A. M. Reza and M. Arami, Removal of reactive blue 19 from aqueous solution by pomegranate residualbased activated carbon: optimization by response surface methodology, J. Environ. Health Sci. Eng., 2014, 12, 1-8.

25 J. K. Im and K. D. Zoh, Application of response surface method to carbamazepine removal in photo-ozonation reaction under alkaline condition, Water Sci. Technol, 2013, 67, 74-80.

26 S. Selvakumar, R. Manivasagan and K. Chinnappan, Biodegradation and decolourization of textile dye wastewater using Ganoderma lucidum, 3 Biotech, 2013, 3, 71-79.

27 N. Vieno, T. Tuhkanen and L. Kronberg, Removal of pharmaceuticals in drinking water treatment: effect of chemical coagulation, Environ. Technol., 2006, 27, 183-192.

28 W. Yang, Y. Wu, L. Zhang, J. Jiang and L. Feng, Removal of five selected pharmaceuticals by coagulation in the 
presence of dissolved humic acids and kaolin, Desalin. Water Treat., 2015, 54, 4-5.

29 A. Kumar and I. Xagoraraki, Human health risk assessment of pharmaceuticals in water: an uncertainty analysis for meprobamate, carbamazepine, and phenytoin, Regul. Toxicol. Pharmacol., 2010, 57, 146-156.
30 S. W. Nam, B. Jo, Y. Yoon and K. D. Zoh, Occurrence and removal of selected micropollutants in a water treatment plant, Chemosphere, 2014, 95, 156-165.

31 K. E. Pinkston and D. L. Sedlak, Transformation of aromatic ether- and amine-containing pharmaceuticals during chlorine disinfection, Environ. Sci. Technol., 2014, 38, 4019-4025. 